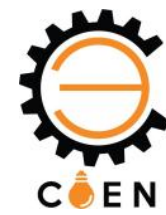

\title{
MODELAGEM DE UM VEÍCULO COM MOTOR DE COMBUSTÃO INTERNA E VALIDAÇÃO COM DADOS DE UM CICLO DE CONDUÇÃO REAL
}

\author{
Wenderson Cirilo Silva de Paula ${ }^{(1)}$ (endersoncsdep@gmail.com),Tarsis Prado Barbosa ${ }^{(1,2)}$ \\ (tarsisbarbosa@ufsj.edu.br), Leonardo Adolpho Rodrigues da Silva ${ }^{(1)}$ (leonardo@ufsj.edu.br), Juan Carlos \\ Horta Gutiérrez ${ }^{(2)}$ (horta@demec.ufmg.br) \\ ${ }^{(1)}$ Universidade Federal de São João del-Rei (UFSJ) - Dep. das Engenharias de Telecom. e Mecatrônica - Ouro Branco - MG \\ ${ }^{(2)}$ Universidade Federal de Minas Gerais (UFMG) - Dep. de Engenharia Mecânica - Belo Horizonte - MG
}

RESUMO: Este trabalho tem como objetivo desenvolver modelos computacionais de um veículo de carga em dois programas de simulação diferentes - Advisor e Amesim, visando investigar as possibilidades $e$ limitaçães de ambos. Os modelos foram simulados em um ciclo de condução obtido em um trajeto realizado com o veículo real. O erro da média de consumo de combustível dos dois modelos implementados foi menor que $2 \%$ em relação ao valor medido com o veículo real no percurso estudado.

PALAVRAS-CHAVE: Modelagem Computacional, Trem de Potência, Análise de Consumo, Análise de Desempenho.

\section{INTRODUÇÃO}

Ao longo dos últimos anos o crescimento da indústria automobilística juntamente com a sua cadeia de suplementos (principal responsável pela produção e comercialização de veículos e autopeças), promoveu inúmeros benefícios e melhorias na mobilidade humana e passou a ter uma presença marcante no cenário mundial, influenciando diretamente o desenvolvimento econômico e social (TRINDADE, 2016).

No entanto, a rápida expansão do mercado automobilístico também passou a apresentar inúmeras desvantagens, devido ao uso de motores de combustão interna (MCI) em seus veículos, resultando no surgimento de problemas energéticos, ambientais e sociais (TRINDADE, 2016; ARAÚJO, 2015). Dentro destes problemas pode-se destacar: 1 - a rápida elevação do preço do combustível devido ao rápido crescimento do número de veículos aliado a redução das reservas mundiais de petróleo; 2 - problemas relacionados à saúde da população nos grandes centros urbanos devido à emissão de gases poluentes no processo de queima do combustível; 3 - aumento das preocupações relacionadas à influência das emissões automotivas sobre o meio ambiente, em especial relacionadas à emissão do $\mathrm{CO}_{2}$, tido como principal responsável pelo aquecimento global (TRINDADE, 2016; BASTOS, 2003; OLIVEIRA; NOGUEIRA e HORTA, 2018; BERTON e BADUY, 2012).

Diante de tais problemas, o governo e a sociedade passaram a exigir das montadoras o desenvolvimento de veículos cada vez mais eficientes e menos poluentes (SEQUENZ, 2012). Na busca de desenvolver produtos mais eficientes e em menor tempo, a indústria automotiva passou a utilizar ferramentas computacionais para o desenvolvimento de seus projetos. O uso dessas ferramentas permitiu a redução do número de protótipos nas fases iniciais, permitindo inclusive a redução dos custos envolvidos nesse desenvolvimento (BERTO, 2015).

Uma das principais aplicações das ferramentas computacionais em projetos automobilísticos é o desenvolvimento de modelos para a realização de análises das diferentes configurações possíveis para o trem de potência de um automóvel (OLIVEIRA; NOGUEIRA e HORTA, 2018). O trem de potência é o sistema responsável por transferir a potência fornecida pelo motor para as rodas do veículo, permitido que o veículo supere as forças de resistência ao seu movimento. Este sistema geralmente é composto por vários elementos como: motor (gasolina, diesel, ou elétrico), 

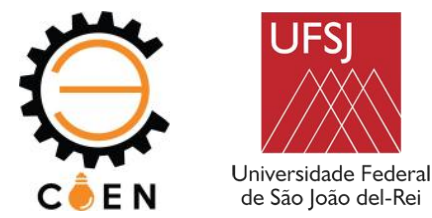

de São João del-Rei

embreagem, transmissão (manual ou automática), semieixos, diferencial e rodas (X-ENGINEER, 2019).

Nos veículos convencionais a simulação do trem de potência através de um ciclo de condução tem como principal objetivo determinar o possível desempenho, consumo, eficiência e os níveis de emissões de gases poluentes. Isso permite aos engenheiros, responsáveis pelo desenvolvimento do automóvel avaliar as configurações propostas determinando as possíveis melhorias e descartando as configurações ruins, mediante os requisitos estabelecidos pelo projeto (BERTO, 2015). Neste contexto, é essencial que o modelo do veículo seja calibrado e validado com dados reais ou experimentais.

Diante disso, este trabalho tem como objetivo apresentar o processo de desenvolvimento e validação de dois modelos computacionais baseados em parâmetros de um veículo real, utilizando os programas Amesim e o Advisor. Os modelos foram analisados com base em um ciclo de condução real que foi obtido em um trajeto realizado na cidade de Ouro Branco - MG utilizando uma caminhonete Ford Ranger e um dispositivo conectado a porta OBD-II do veículo.

\section{TRABALHOS RELACIONADOS}

Há inúmeros trabalhos na literatura que buscam avaliar o desempenho de automóveis por intermédio de modelos de trens de potência, de forma a melhorar a resposta do veículo em relação à demanda de potência de um trajeto. Roberts, Dempsey e Picarelli (2013) construíram um modelo computacional utilizando o software Dymola e a linguagem Modelica. O modelo construído abordou conceitos da dinâmica dos fluídos, mapas de emissão de poluentes e mapas de eficiência do motor de combustão interna, permitindo analisar o desempenho do veículo em eventos dinâmicos de direção.

Thomas e Talon (2012) buscaram descrever o processo de elaboração e calibração de modelos baseados nos motores desenvolvidos pela RENAULT com o software Amesim. Os modelos foram construídos para facilitar a realização de melhorias nos sistemas de controle dos motores através da análise dos dados obtidos pela simulação dos mesmos, orientando a tomada de decisão da equipe sobre quais ações deveriam ser adotadas no sistema de controle dos motores para alcançar os objetivos desejados.

No trabalho desenvolvido por Hennek et al. (2017), realizou-se a análise de consumo de um veículo utilizando uma transmissão manual e uma transmissão CVT. A análise do consumo de combustível das duas configurações foi realizada através de simulações computacionais utilizando três ciclos de condução com diferentes dinâmicas de condução e diferentes perfis de velocidade, referentes aos percursos realizados por um veículo real em um trajeto pré-defino na cidade de Opole na Polônia. Os modelos também foram testados em um ciclo de condução sintético padronizado, o NEDC, que era o ciclo de condução utilizado na Europa nos testes de emissões.

Sebeck et al. (2017) realizaram estudos referentes ao consumo de combustível através da simulação modelos de veículos terrestres utilizados pelo exército dos EUA. Nas simulações desenvolvidas pelos autores foram utilizados dois tipos diferentes de ciclos de condução: um comercialmente padronizado e outro obtido através de testes realizados com um veículo militar no circuito de teste padrão do exército dos EUA. Tais simulações permitiram a caracterização de métricas adicionais que influenciam no consumo de combustível deste tipo de veículo por meio da comparação dos resultados obtidos entre as simulações realizadas com os dois tipos de ciclos. 


\section{MATERIAIS E MÉTODOS}

\subsection{Ciclo de condução}

O ciclo de condução é um dos principais parâmetros de entrada para a simulação e avaliação do desempenho de um modelo baseado em um veículo real. O ciclo trata-se de uma curva de velocidade em função do tempo (ou distância percorrida) que representa a forma como o veículo é conduzido durante a realização de um determinado trajeto, incluindo as influências externas como: restrições de velocidade impostas pela sinalização no percurso, presença de curvas, aclives e declives, e perfil de direção do condutor (CORRÊA, SILVA e DEDINI, 2011).

No presente trabalho, o ciclo de condução adotado como parâmetro de entrada para a realização das simulações dos dois modelos propostos foi obtido através da realização de um percurso pré-estabelecido na cidade de Ouro Branco - MG, com um veículo da montadora Ford, modelo Ranger 3.0 XLS do ano de 2012.

O trajeto realizado para a obtenção dos dados é mostrado na Figura 1. A aquisição dos dados foi realizada com um dispositivo ELM327 conectado a saída ODB-II do veículo (Figura 2). O dispositivo permite a transferência via Bluetooth das informações do veículo para um aplicativo de smartphone, que com auxílio do sistema GPS do próprio aparelho permitiu obter informações referentes à posição e velocidade do veículo ao longo do trajeto. $\mathrm{O}$ gráfico do ciclo de condução obtido é apresentado na Figura 3.

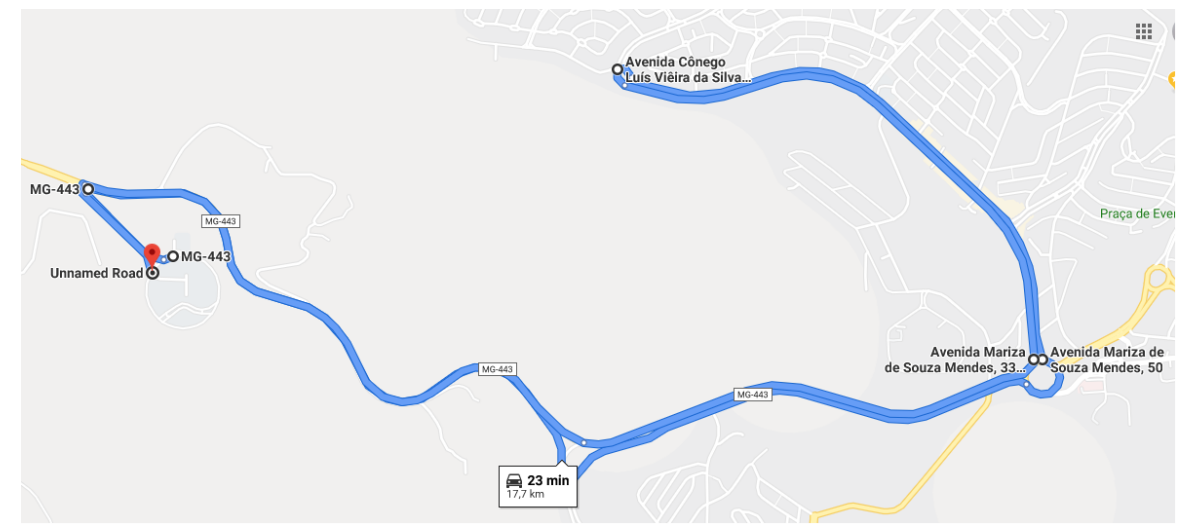

Figura 1. Trajeto realizado para a obtenção do ciclo de condução.

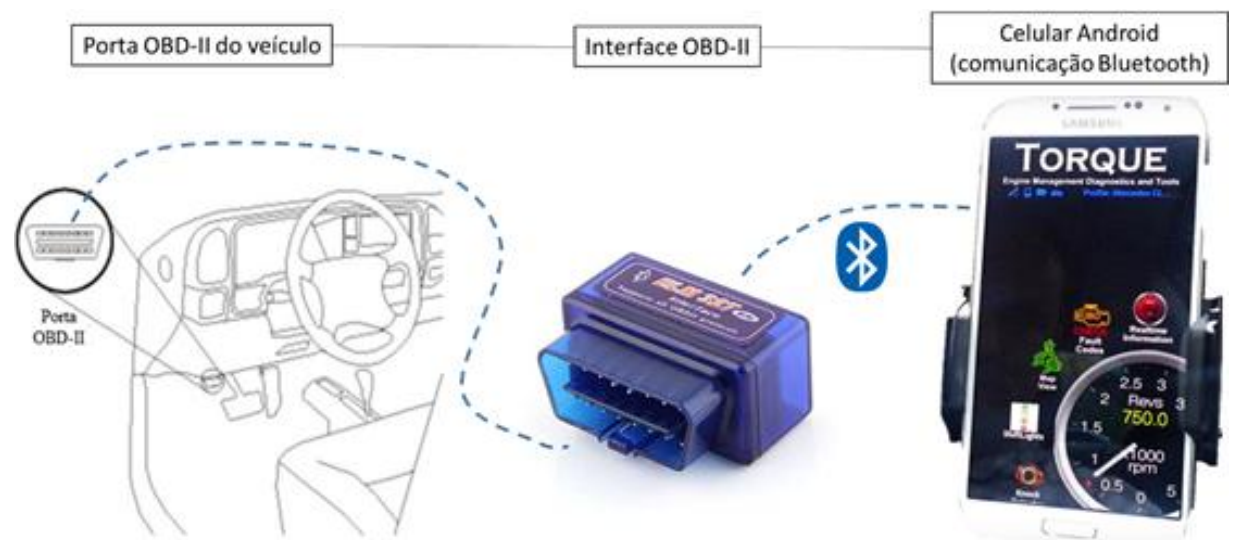

Figura 2. Estrutura do sistema de aquisição de dados. 

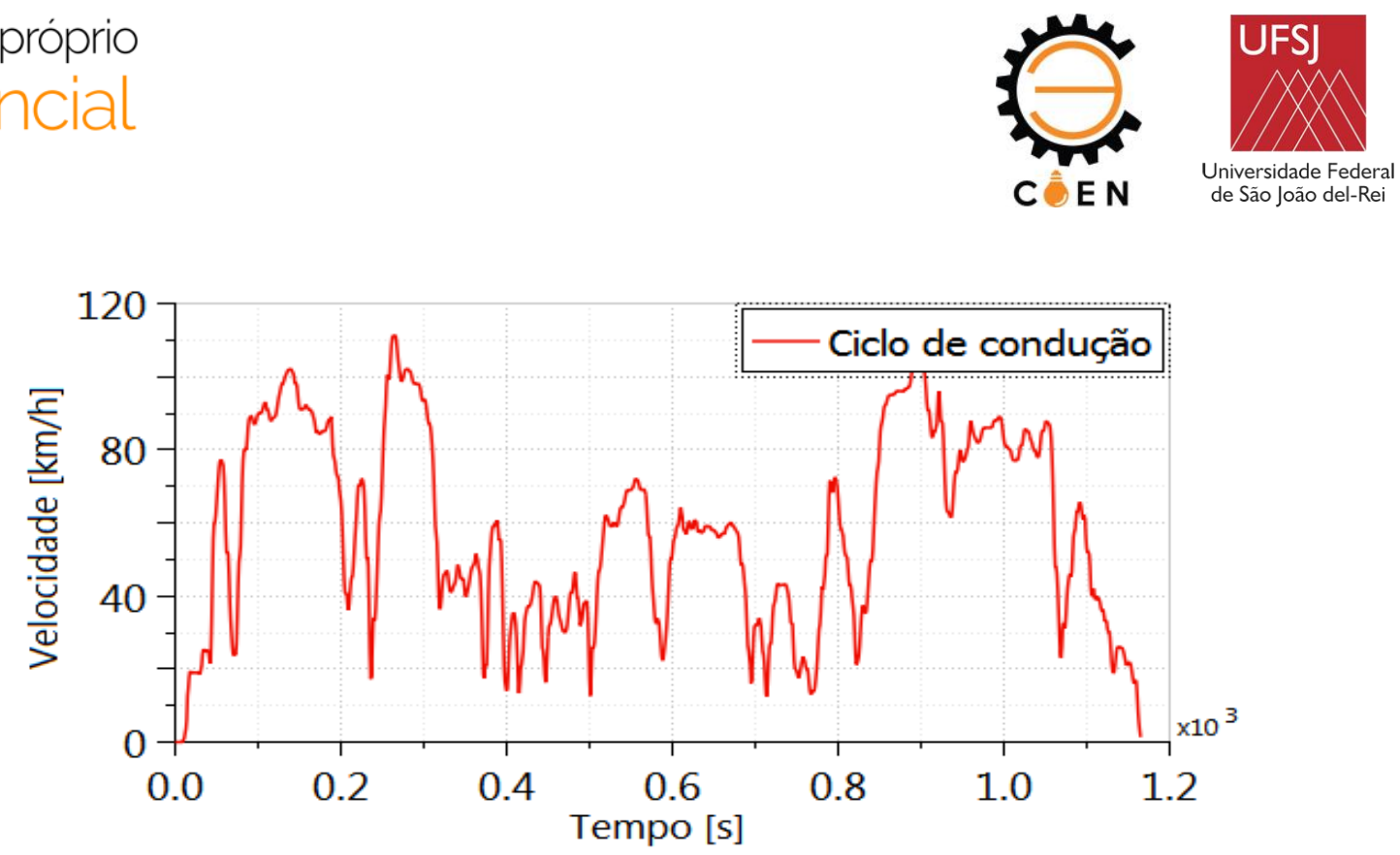

Figura 3. Ciclo de condução obtido real obtido.

A Tabela 1 apresenta algumas características do ciclo de condução obtido.

Tabela 1. Características do ciclo de condução.

\begin{tabular}{ll}
\hline Tempo & $1165 \mathrm{segundos}$ \\
Distância & $18,74 \mathrm{~km}$ \\
Velocidade máxima & $111,33 \mathrm{Km} / \mathrm{h}$ \\
Velocidade média & $57,86 \mathrm{Km} / \mathrm{h}$ \\
Máxima aceleração & $3,76 \mathrm{~m} / \mathrm{s}^{2}$ \\
Máxima desaceleração & $-3,81 \mathrm{~ms}$ \\
Aceleração média & $0,48 \mathrm{~m} / \mathrm{s}^{2}$ \\
\hline
\end{tabular}

\subsection{Parâmetros do veículo}

Nos dois modelos computacionais elaborados foram utilizados os mesmos dados do veículo adotado para obter o ciclo de condução da Figura 3, o que possibilitou avaliar o desempenho de ambos dos modelos com base nos resultados obtidos durante a realização do trajeto apresentado na Figura 1.

Os parâmetros adotados para cada um dos modelos desenvolvidos nos dois softwares analisados neste trabalho são apresentados na Tabela 2 abaixo, e foram obtidos através do manual do veículo Ford Ranger 2012, fornecido pelo fabricante.

Tabela 2. Dados do veículo Ford Ranger XLS 3.0

\begin{tabular}{|c|c|c|c|}
\hline \multicolumn{4}{|c|}{ CARACTERISTICAS DO VÉICULO } \\
\hline \multicolumn{2}{|r|}{ ARQUITETURA } & \multicolumn{2}{|c|}{ DESEMPENHO } \\
\hline Tipo de veículo & $\begin{array}{l}\text { Carroceria monobloco, } 4 \text { portas, } \\
5 \text { lugares }\end{array}$ & $\begin{array}{l}\text { Velocidade } \\
\text { máxima }\end{array}$ & $170 \mathrm{Km} / \mathrm{h}$ \\
\hline $\begin{array}{l}\text { Coeficiente } \\
\text { aerodinâmico }\end{array}$ & 0,44 & $\begin{array}{l}\text { Aceleração de } 0 \\
\text { a } 100 \mathrm{Km} / \mathrm{h}\end{array}$ & $12,9 \mathrm{~s}$ \\
\hline Densidade do ar & $1,22 \mathrm{Kg} / \mathrm{m}^{3}$ & Consumo médio & $11 \mathrm{Km} / \mathrm{L}$ \\
\hline \multicolumn{4}{|c|}{ MOTOR DE COMBUSTÂO INTERNA } \\
\hline \multicolumn{2}{|r|}{ ARQUITETURA } & \multicolumn{2}{|c|}{ CARACTERISTICAS } \\
\hline $\begin{array}{l}\text { Inte } \\
\text { dial }\end{array}$ & $\begin{array}{l}\text { national Power } \\
\text { teiro, longitudinal, } 4 \text { cilindros } 3.0 \mathrm{~L} \text {, }\end{array}$ & $\begin{array}{l}\text { Taxa de } \\
\text { Compressão }\end{array}$ & $17: 1$ \\
\hline
\end{tabular}




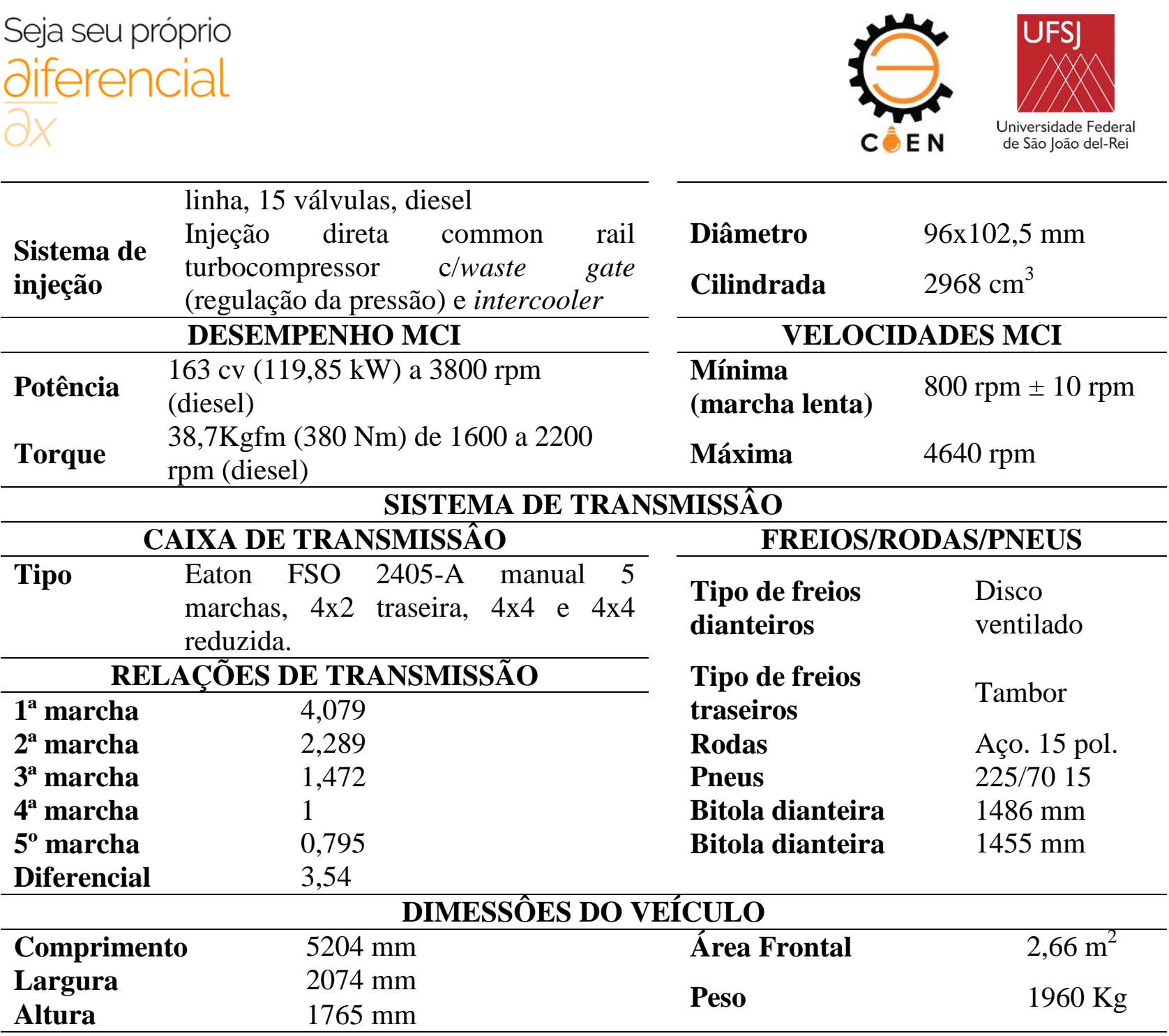

\subsection{Modelagem no ADVISOR}

O Advisor (Advanced Vehicle Simulator) consiste em um sistema de código aberto com vários modelos de veículos desenvolvidos na linguagem de programação gráfica e orientada a objetos do software MATLAB/Simulink (CUDDY e WIPKE, 2019). O programa apresenta cinco configurações diferentes de trem de potência incluindo modelos de arquiteturas convencionais, híbridos elétricos com baterias e com células de combustíveis (NATIONAL RENEWABLE ENERGY LABORATORY, 2019).

Os modelos do Advisor são modelos quase-estáticos baseados em dados empíricos, obtidos através das relações de entrada/saída dos componentes durante a realização de testes em laboratório (NATIONAL RENEWABLE ENERGY LABORATORY, 2019). A base de dados do Advisor é utilizada como referência na área de simulação computacional de veículos, sendo possível obter modelos com erros próximos de $2 \%$ em relação aos dados de veículos reais (CUDDY e WIPKE, 2019).

Diante disso, no presente trabalho os dados do veículo Ford Ranger e do ciclo de condução obtido foram inseridos no modelo de um veículo convencional com motor diesel disponibilizado pelo Advisor (Figura 4). O mapa de eficiência de um motor diesel de 6.3L disponibilizado no Advisor foi ajustado através de um fator de escalonamento para a potência do motor da Ford Ranger. Posteriormente os resultados obtidos neste programa foram comparados com o modelo desenvolvido no Amesim. 

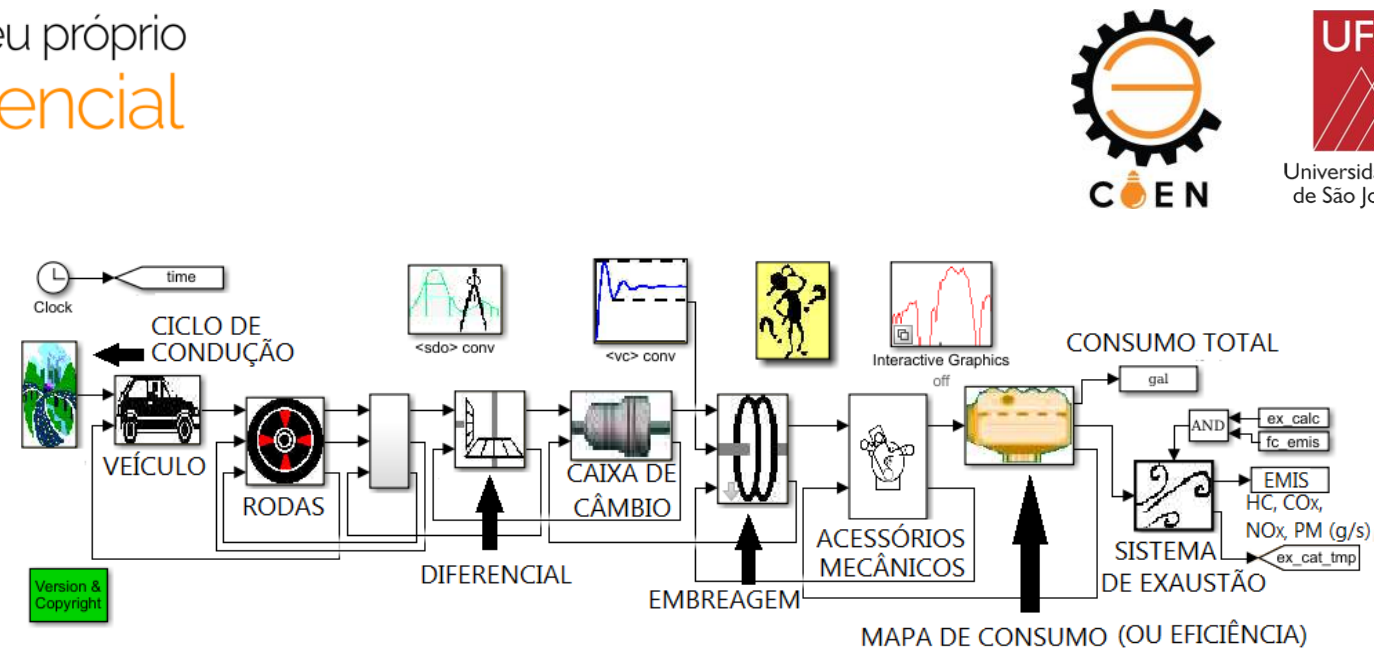

Figura 4. Diagrama do trem de potência do veículo convencional disponível no Advisor.

\subsection{Modelagem no Amesim}

O Amesim é um software desenvolvido pela empresa Imagine S.A., posteriormente adquirida pela LMS Engineering Innovation em 2007 (SIEMENS PLM SOFTWARE, 2019). Este software consiste em um sistema computacional baseado no método por fluxo que permite a simulação unidimensional do comportamento dinâmico de modelos com vários domínios energéticos (BERTON e BADUY, 2012). Também é possível a realização de simulações integradas com dados obtidos em testes físicos reais e utilizando modelos desenvolvidos em outros softwares como MATLAB, Open Modellica e integração com sistemas CAD/CAE para realização de simulações tridimensionais.

Além das bibliotecas prontas disponíveis, há também a possibilidade de desenvolvimento de novos componentes, através do módulo de edição de modelos (Ameset). No âmbito deste trabalho, o programa apresenta uma biblioteca de componentes totalmente dedicados à modelagem e simulação de sistemas automotivos, denominada "IFP Drive". Devido a todos os benefícios apresentados, o Amesim foi um dos programas escolhidos para a elaboração do presente trabalho. O modelo do trem de potência do veículo Ford Ranger 2012 implementado no Amesim é mostrado na Figura 5, tendo sido adotado os mesmos parâmetros utilizados no modelo construído do Advisor, com exceção do mapa de eficiência.

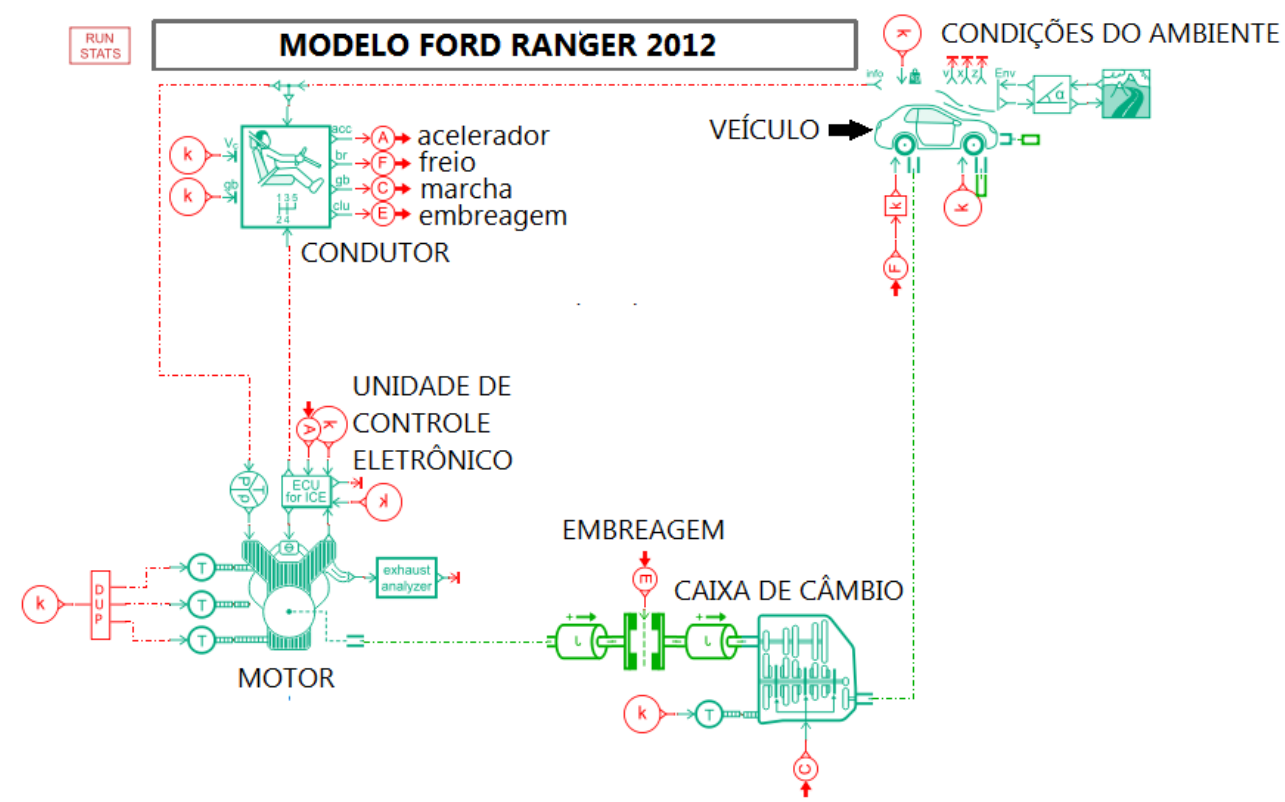

Figura 5. Modelo do veículo desenvolvido no Amesim. 
As curvas de torque máximo em função da rotação do motor de combustão interna simulado no Advisor foram fornecidas para o Amesim, possibilitando a construção da curva de potência e do mapa de eficiência do motor. Para a construção desse mapa foram fornecidos também alguns dados adicionais referentes ao motor: número de cilindros, curso do pistão, volume total do motor em litros, vetor de toque máximo do motor, entre outros. Todos estes parâmetros estão disponíveis na Tabela 2 e na Tabela 3, que apresenta os valores do vetor torque máximo em função da velocidade do motor de combustão interna (MCI).

Tabela 3. Vetores de torque e rotação máxima adotados para o MCI.

\begin{tabular}{cc}
\hline Velocidade do MCI $(\mathbf{r p m})$ & Torque $\mathbf{( N m})$ \\
\hline 1000 & 257 \\
1600 & 387,6 \\
2200 & 387,6 \\
2800 & 367,2 \\
3400 & 336,6 \\
4000 & 285,6 \\
\hline
\end{tabular}

Além destes parâmetros, também foi necessário fornecer dados referentes às características do combustível utilizado pelo motor, que neste caso foi o diesel. Os valores referentes às características físico-químicas deste combustível são apresentados na Tabela 4 (MORETTI, 2013).

Tabela 4. Características físico-químicas do diesel (MORETTI, 2013).

\begin{tabular}{ll}
\hline Densidade & $853 \mathrm{Kg} / \mathrm{m}^{3}$ \\
Poder calorífico inferior & $42,65 \mathrm{MJ} / \mathrm{Kg}$ \\
\hline
\end{tabular}

Com a adoção dos valores apresentados na Tabela 2, na Tabela 3 e na Tabela 4 foi possível obter a curvas de torque e potência apresentadas na Figura 6 e o mapa de eficiência do motor apresentado na Figura 7.

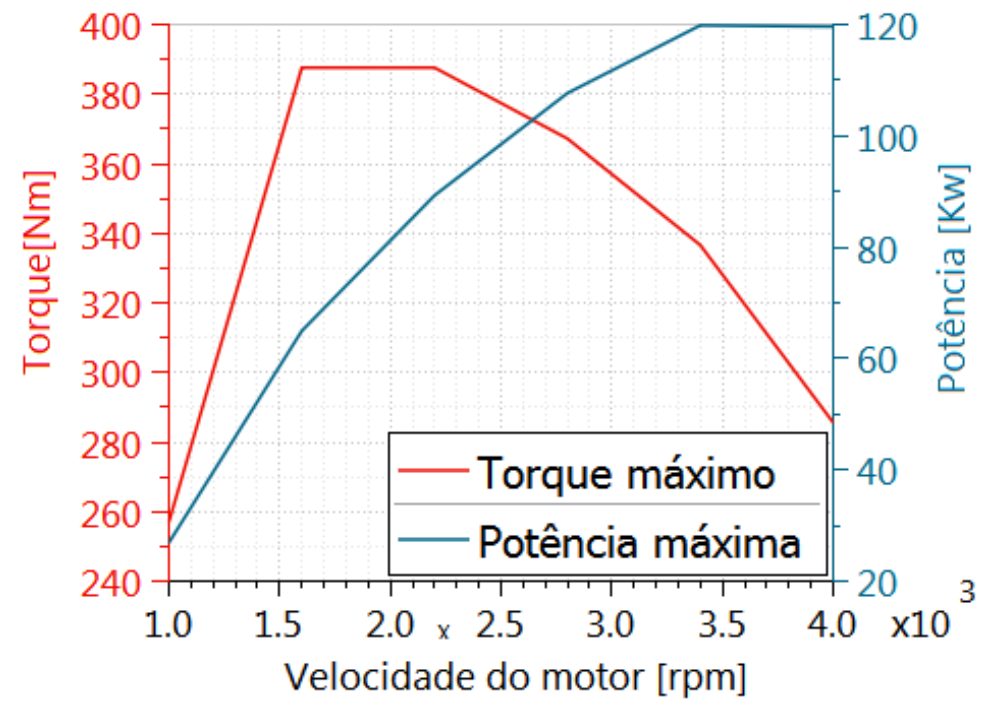

Figura 6. Curvas de torque e potência máxima implementadas no Amesim. 


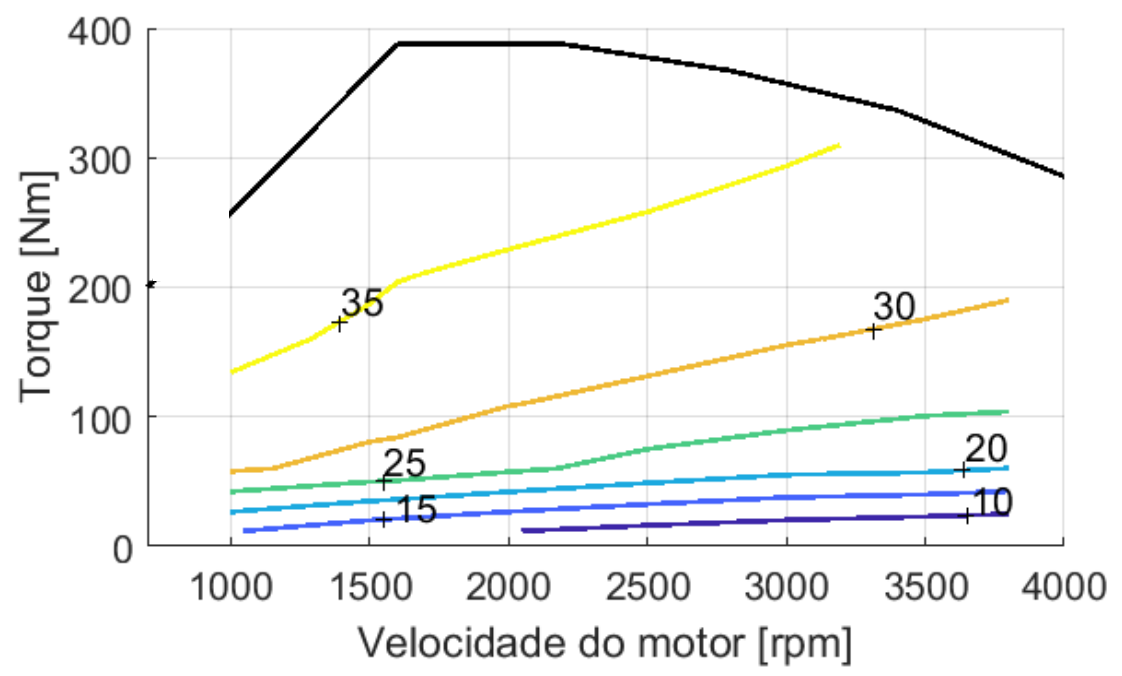

Figura 7. Mapa de eficiência teórico gerado pela ferramenta do Amesim para o motor a diesel do veículo Ford Ranger 2012.

\section{RESULTADOS E CONCLUSÕES}

Os resultados apresentados nesta seção foram obtidos através das simulações de ambos dos modelos propostos na seção anterior utilizando como entrada o ciclo de condução da Figura 3. Também deve se destacar que durante o processo de simulação de cada um dos modelos propostos, foi adotado o mesmo perfil de mudança de marchas obtido pelo algoritmo de controle da transmissão manual do Advisor. Este perfil de marchas encontra-se apresentado na Figura 8.

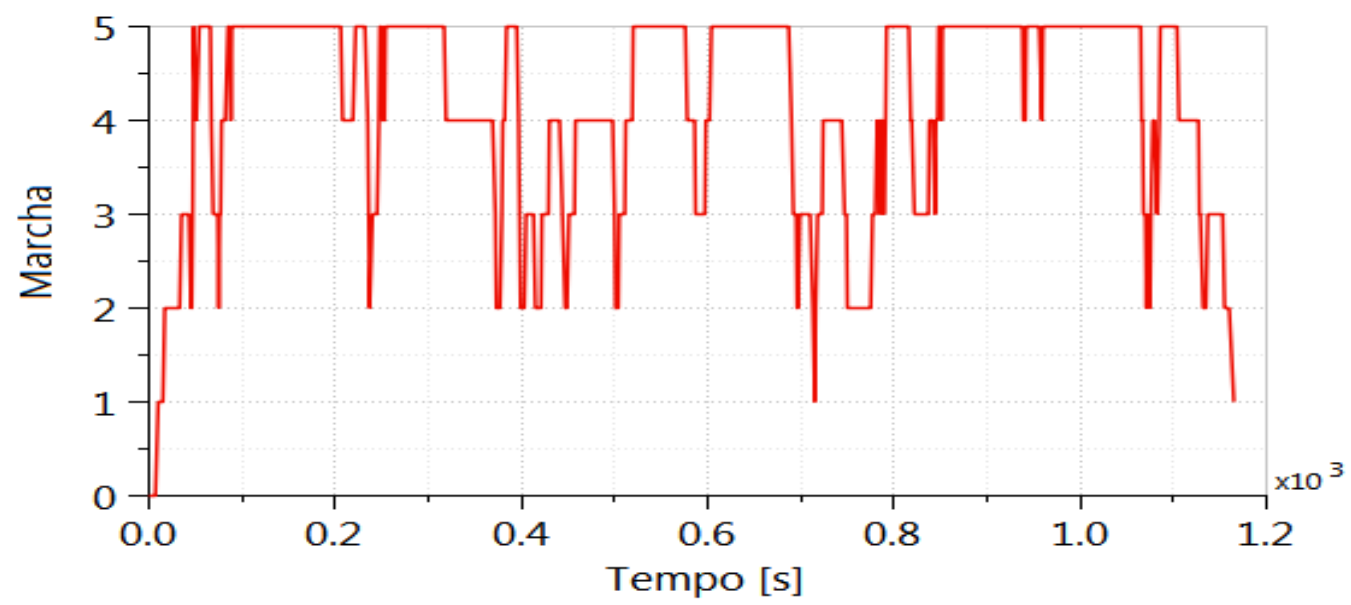

Figura 8. Perfil de seleção de marchas adotado em ambos os modelos.

\subsection{Modelo do Advisor}

A Figura 9 mostra os perfis de velocidade do ciclo de condução (em azul) usado como parâmetro de entrada da simulação e o obtido pelo modelo do Advisor (em vermelho). Neste gráfico é possível ver que o modelo conseguiu seguir o perfil de referência. Os desvios de velocidade alcançaram valores próximos a $6 \mathrm{Km} / \mathrm{h}$ de diferença entre a velocidade do veículo e a apresentada pelo ciclo de condução (Figura 10). 

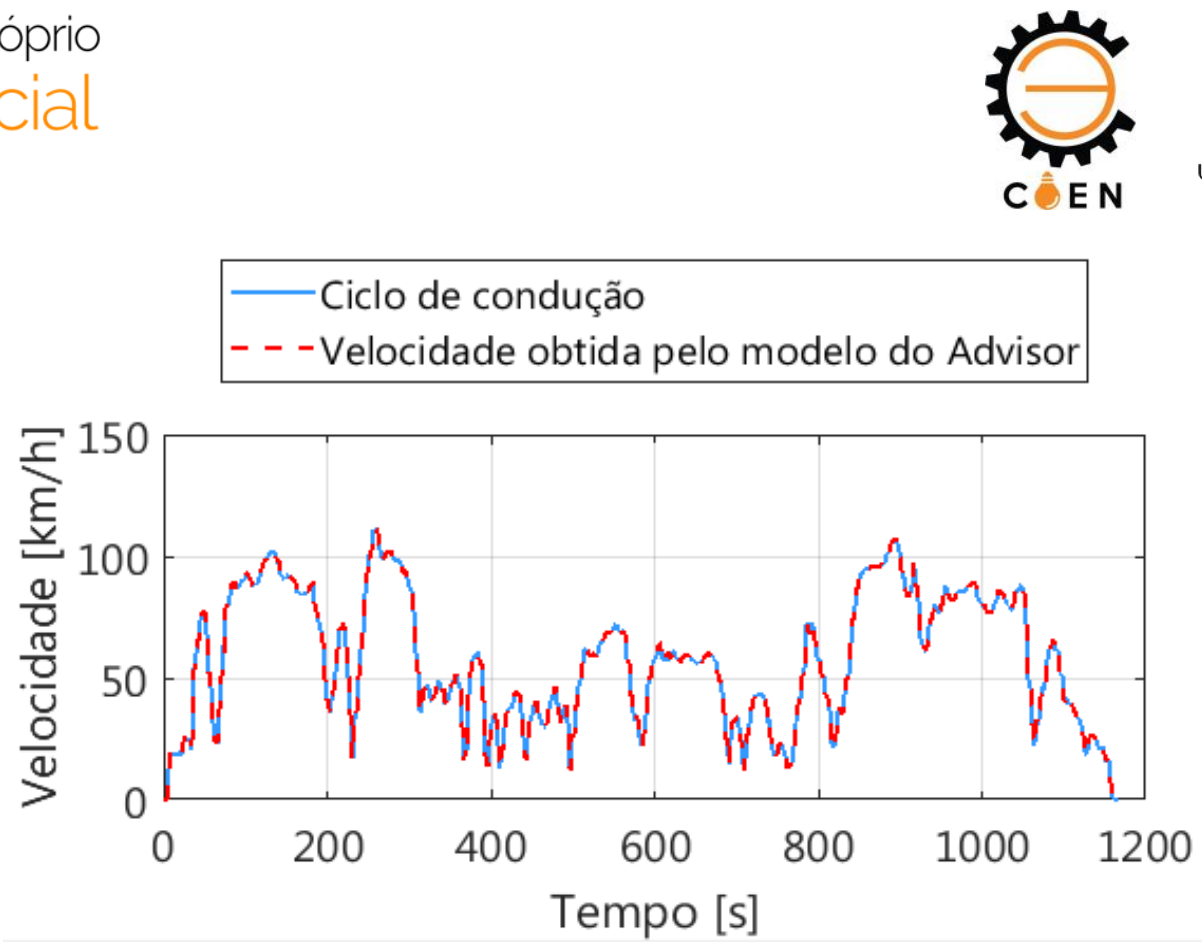

Figura 9. Comparação entre o perfil de velocidade obtido pelo veículo durante a simulação do modelo do Advisor (em vermelho) e o perfil de velocidade exigido pelo ciclo de condução (em azul).

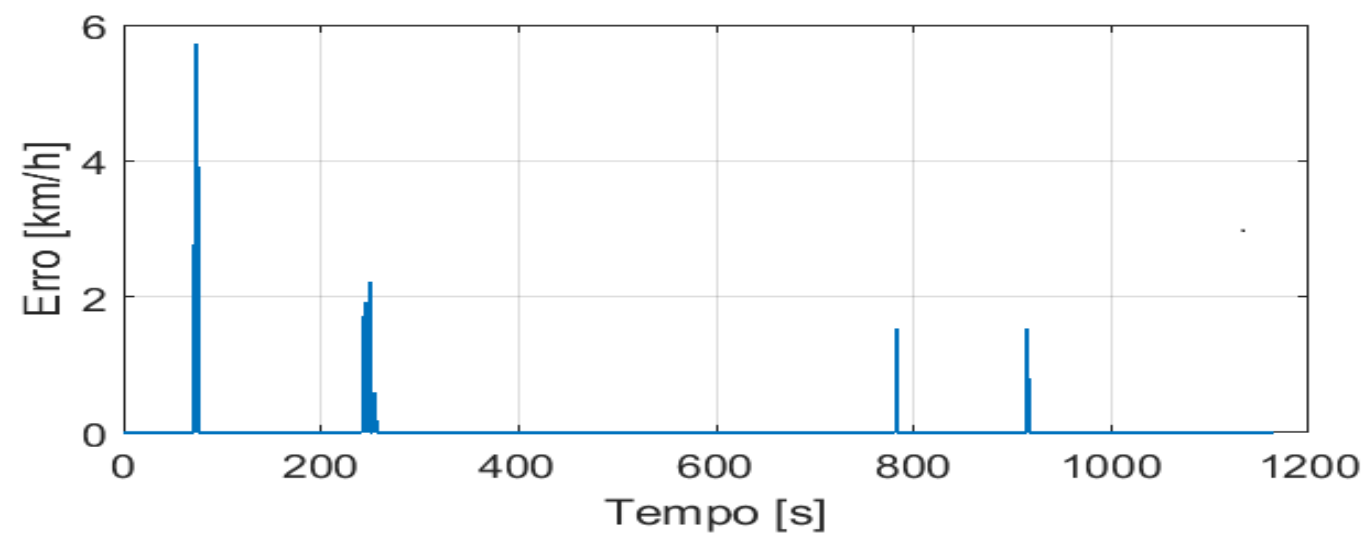

Figura 10. Erro (em $\mathrm{Km} / \mathrm{h}$ ) entre a velocidade obtida pelo modelo do Advisor com a velocidade designada pelo ciclo de condução.

A Figura 11 apresenta os dados obtidos com a Ford Ranger no trajeto real. São mostrados os pontos de operação do motor (rotação) correlacionados à velocidade apresentada pelo veículo real. A distribuição de pontos de forma a constituir diferentes linhas permite inferir como foi à troca de marchas durante o trajeto e é possível verificar que o motor operou no intervalo entre 750 e 3000 rpm, aproximadamente. Além disso, verifica-se que houve uma maior distribuição de pontos para se obter velocidades entre 60 e $110 \mathrm{~km} / \mathrm{h}$, que podem ser relacionados a utilização da $5^{\mathrm{a}}$ marcha. 


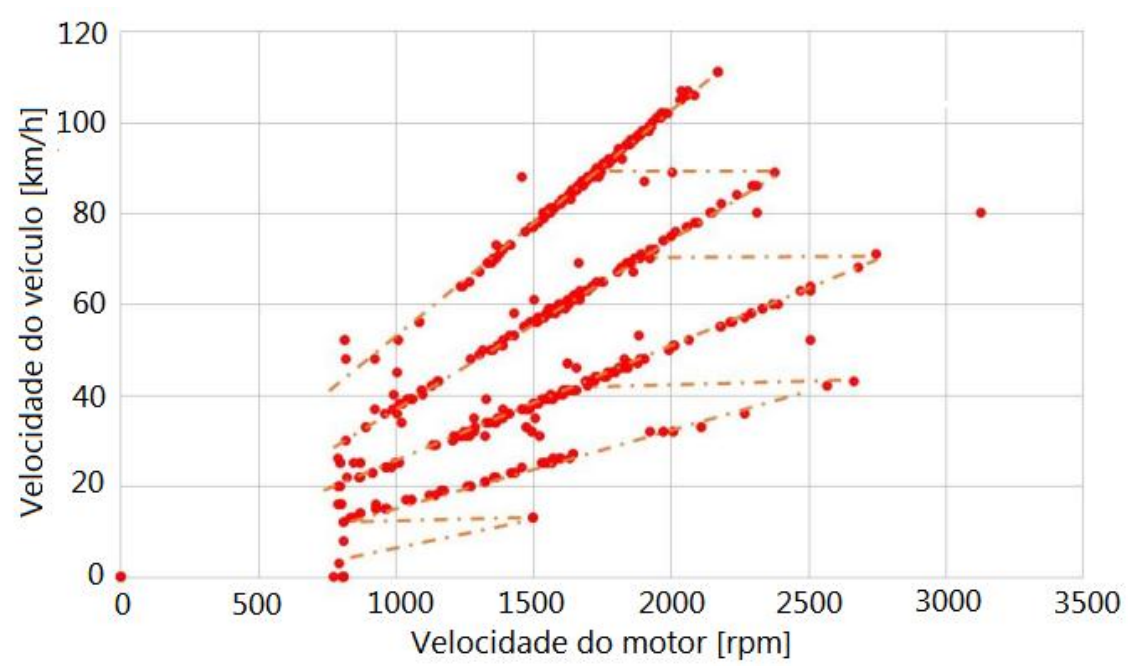

Figura 11: Velocidades do veículo real em função da rotação do motor.

O gráfico apresentado na Figura 12 apresenta a correlação entre as velocidades do veículo e do MCI obtidas através da simulação do modelo desenvolvido no Advisor. Comparando este gráfico com o gráfico da Figura 11, pode-se observar que os coeficientes angulares das retas obtidas pela junção dos pontos são muito semelhantes em ambas as figuras, permitindo confirmar que o controle de trem de potência do Advisor atuou de forma satisfatória. Também é possível notar que a estratégia de seleção de marchas adotada abrangeu um intervalo de velocidades do motor muito próximo aos valores apresentados na Figura 11, tendo atingido rotações próximas a $3000 \mathrm{rpm}$, no entando, o controlador do Advisor escolheu predominantemente o uso da quinta marcha abrangendo velocidades de 40 a $110 \mathrm{Km} / \mathrm{h}$.

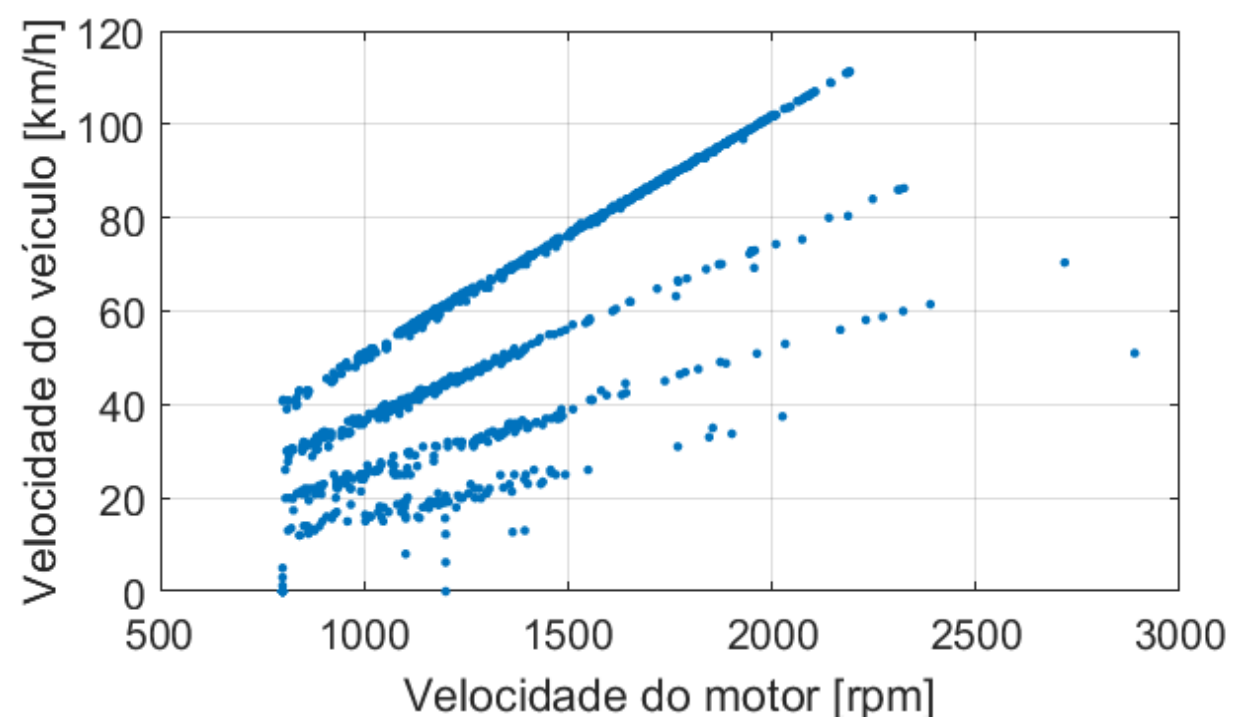

Figura 12: Distribuição das velocidades do veículo em função da velocidade de rotação do motor - Advisor.

Em relação aos pontos de operação do motor de combustão interna obtidos no Advisor durante a simulação no ciclo de condução real é possível ver na Figura 13 que estes pontos (em vermelho) se encontram concentrados em regiões de menor eficiência do MCI, ou seja, em regiões em que há um menor aproveitamento da energia fornecida pelo combustível. 

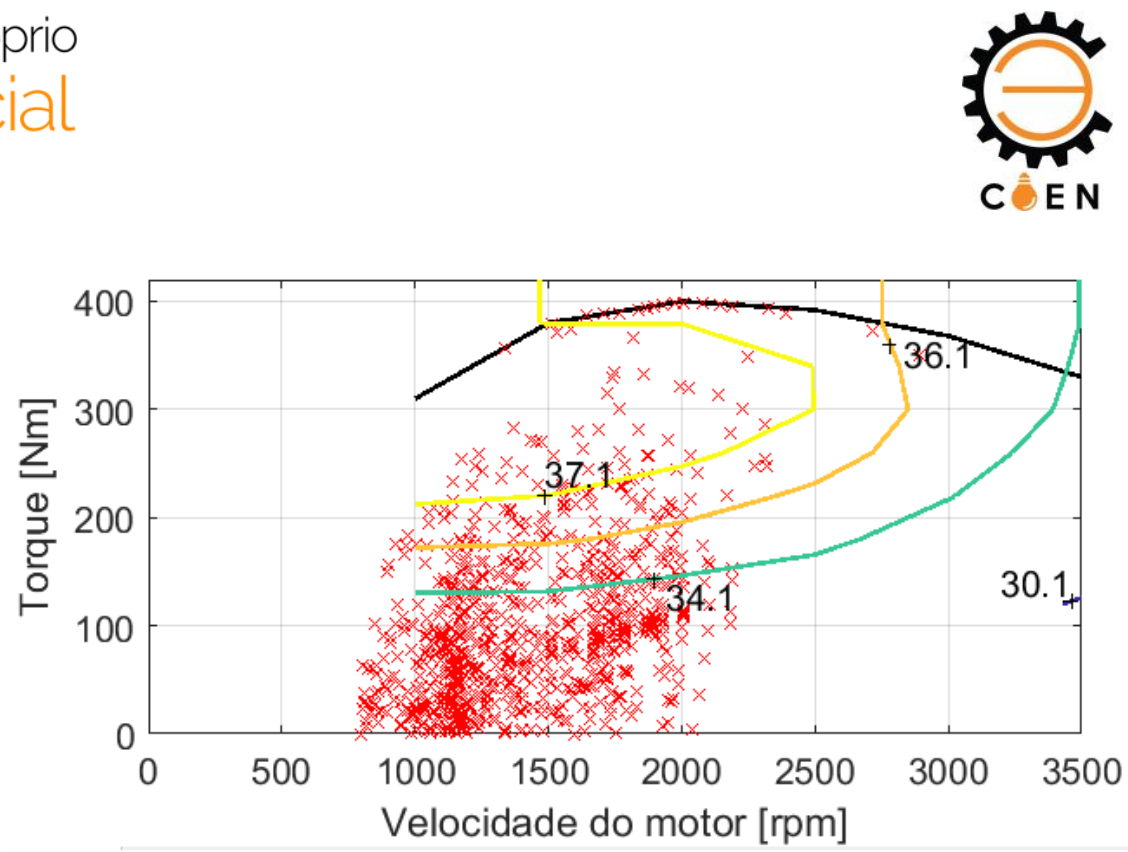

Figura 13. Mapa de eficiência e distribuição dos pontos de operação do motor - Advisor.

Na Tabela 5 encontra-se a comparação entre valores reais obtidos de consumo e de distância percorridos pelo veículo durante o trajeto real e os valores estimados pelo modelo do Advisor, no qual é possível notar que o erro apresentado pelo modelo foi inferior a $2 \%$.

Tabela 5. Comparação entre os valores obtidos na simulação do modelo do Advisor e os dados de consumo e distância percorrida, mensurados durante a realização do trajeto da Figura 1.

\begin{tabular}{lcc}
\hline Modelo & Distância $(\mathbf{k m})$ & Consumo $(\mathbf{k m} / \mathbf{L})$ \\
\hline Veículo real & 18,74 & 9,60 \\
Modelo do ADVISOR & 18,71 & 9,53 \\
\hline Erro $(\%)$ & 0,16 & 0,73 \\
\hline
\end{tabular}

\subsection{Modelo do Amesim}

A Figura 14 correlaciona as curvas de velocidade do ciclo de condução (em azul) com os obtidos pelo modelo do Amesim (em vermelho). O modelo conseguiu seguir o ciclo, apresentando alguns desvios apenas em alguns momentos de elevadas acelerações. O modelo do Amesim apresentou discrepâncias maiores de velocidade que os apresentados pelo modelo do Advisor, conforme mostrado na Figura 15.

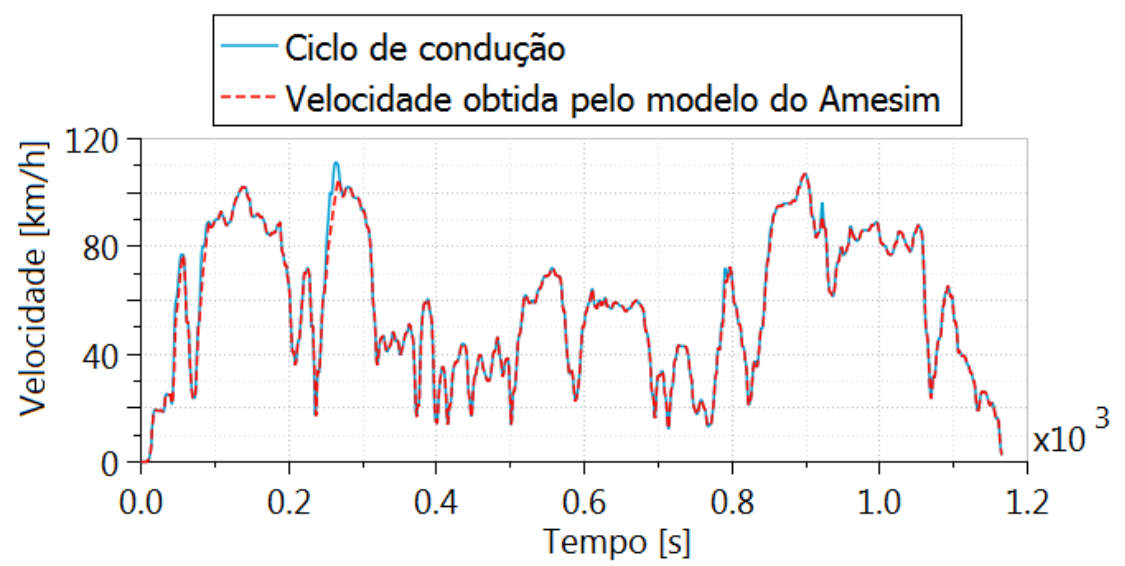

Figura 14. Comparação entre o perfil de velocidade obtido pelo veículo durante a simulação do modelo do Amesim (em vermelho) e o perfil de velocidade exigido pelo ciclo de condução (em azul). 

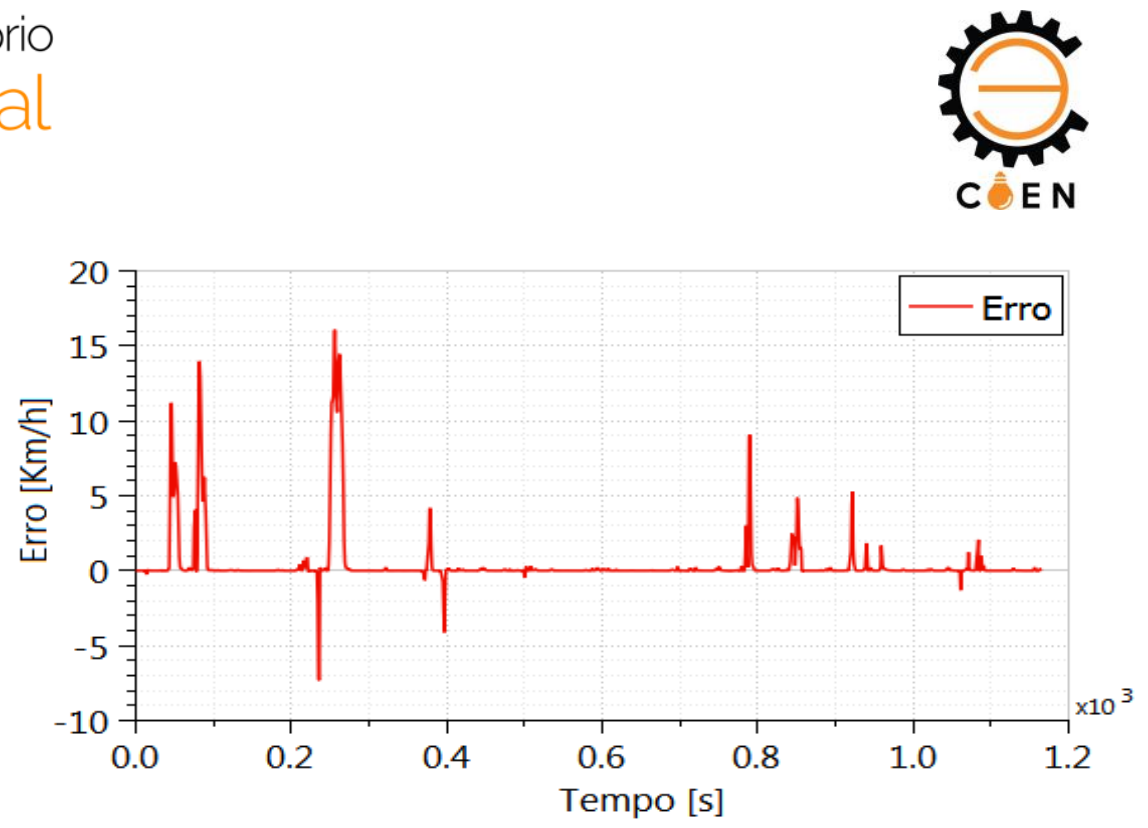

Figura 15. Erro (em Km/h) entre a velocidade obtida pelo modelo do Amesim com a velocidade designada pelo ciclo de condução.

No modelo implementado no Amesim o motorista foi substituído por um controlador PI (proporcional e integral) que busca manter a velocidade do veículo igual à velocidade de referência. O gráfico apresentado na Figura 16 apresenta a correlação entre as velocidades do veículo e do MCI do modelo simulado. Fazendo a comparação da Figura $11 \mathrm{com}$ a Figura 16, pode-se observar que os coeficientes angulares das retas obtidas pela junção dos pontos são similares nas duas figuras e que o controlador utilizado atuou de forma satisfatória. É possível notar que a estratégia de seleção de marchas adotada abrangeu um intervalo de velocidades do motor maior que as analisadas na Figura 11, tendo atingido rotações próximas a $4000 \mathrm{rpm}$. Também é possível notar que o modelo do Amesim, da mesma forma que o modelo do Advisor, fez o uso predominante da quinta marcha abrangendo velocidades de 40 a $110 \mathrm{Km} / \mathrm{h}$, uma vez que ambos os modelos adotaram a mesma estratégia de mudança de marcha (Figura 8).

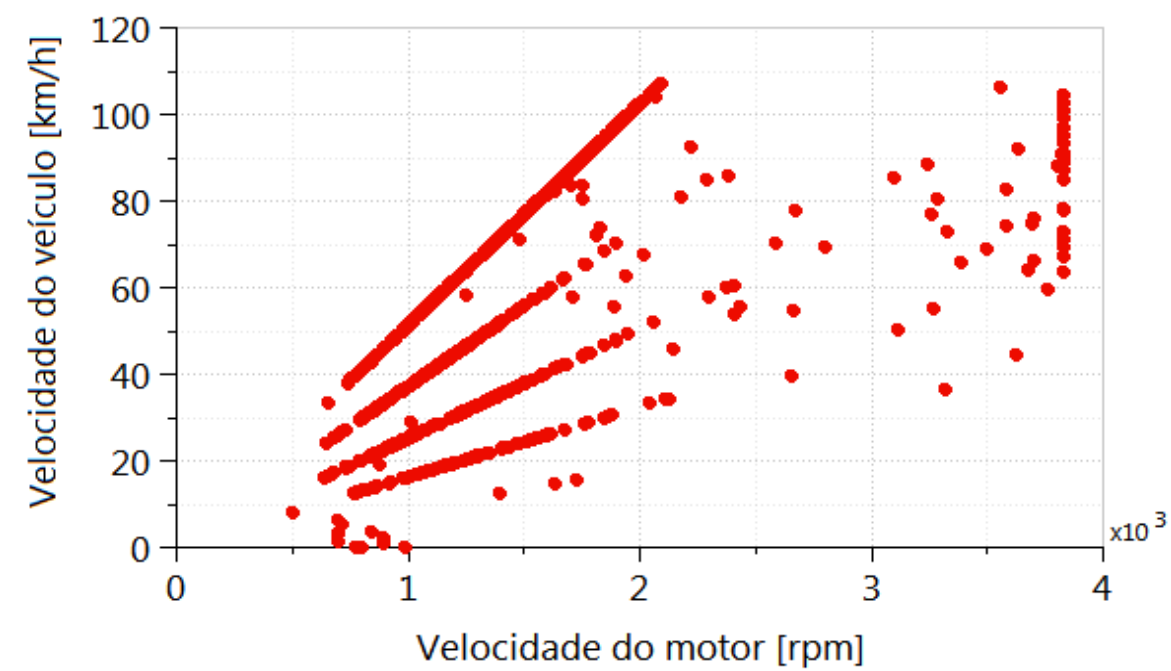

Figura 16. Distribuição das velocidades do veículo em função da velocidade de rotação do motor Amesim.

Na Figura 17 é mostrado os pontos de operação do MCI no ciclo de condução utilizado. A distribuição dos pontos de operação está bem similar à obtida no Advisor (Figura 13). 

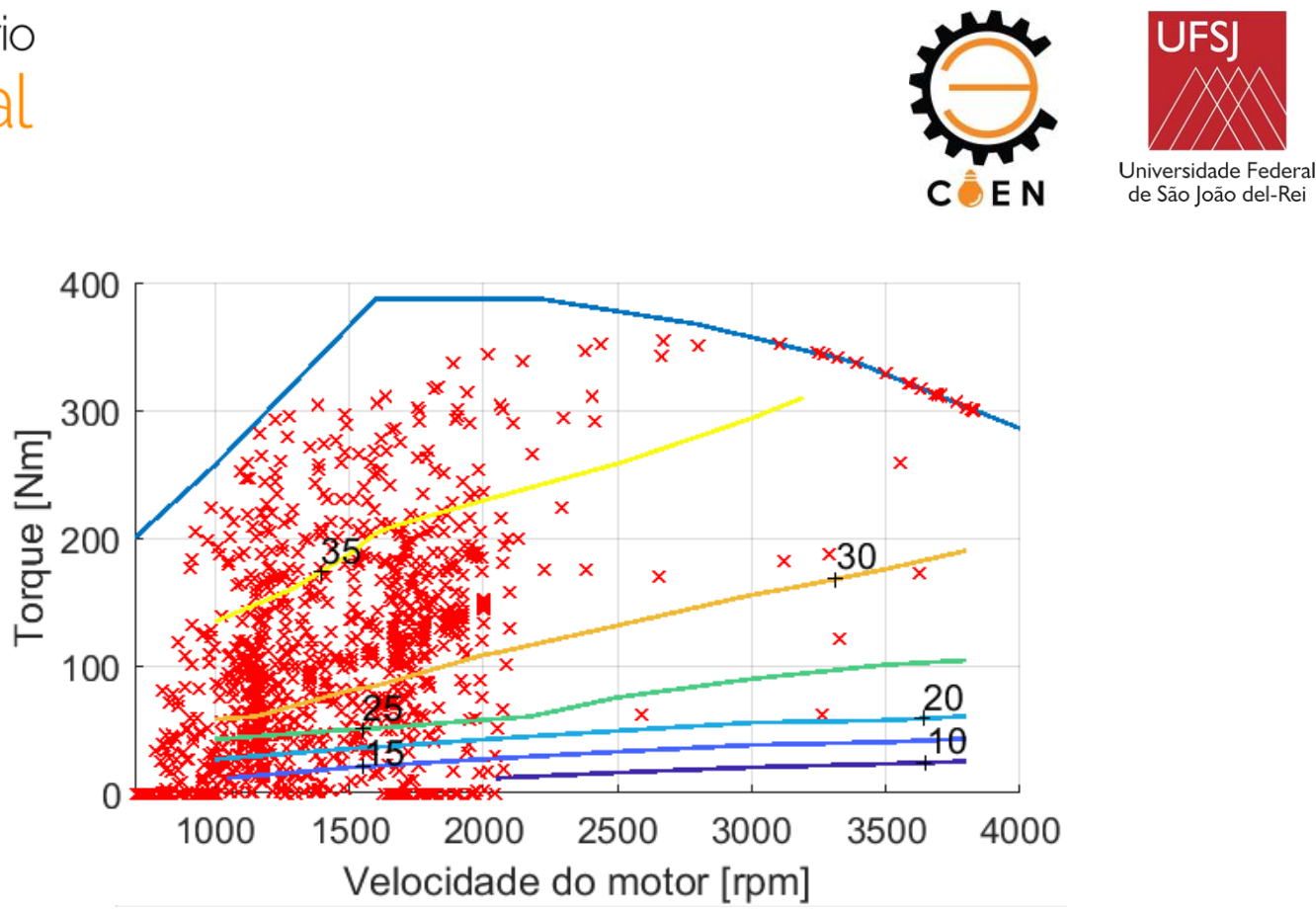

Figura 17. Mapa de eficiência e distribuição dos pontos de operação do motor no ciclo de condução adotado - Amesim.

Na Tabela 5 encontra-se a comparação entre valores reais obtidos de consumo e de distância percorridos pelo veículo durante o trajeto real e os valores estimados pelo modelo do Amesim. Em especial, o erro da média de consumo em $\mathrm{km} / \mathrm{L}$ foi maior do que o obtido com o Advisor $(0,73 \%$ Tabela 4 contra $1,98 \%$ ).

Tabela 5. Comparação entre os valores obtidos na simulação do modelo do Amesim e os dados de consumo e distância percorrida, mensurados durante a realização do trajeto da Figura 1.

\begin{tabular}{lcc}
\hline Modelo & Distância $(\mathbf{k m})$ & Consumo $(\mathbf{k m} / \mathbf{L})$ \\
\hline Veículo real & 18,74 & 9,60 \\
Modelo do Amesim & 18,54 & 9,41 \\
\hline Erro (\%) & 1,07 & 1,98 \\
\hline
\end{tabular}

Os desvios de velocidade do modelo em momentos de maiores acelerações, conforme indicado na Figura 15 podem estar relacionados ao fato de que o modelo do Amesim, apesar de ter recebido grande parte dos dados do modelo do Advisor, para o cálculo da força de resistência ao rolamento dos pneus possui um modelo próprio. Sendo assim, a estratégia de mudança de marcha fornecida pelo Advisor deveria ter sido ligeiramente alterada para se conseguir seguir melhor o trajeto.

\subsection{Conclusões}

Os modelos construídos de um veículo real nos dois programas, Advisor e Amesim apresentaram valores de erro em relação a média de consumo de combustível inferior a $2 \%$ em comparação com os valores obtidos em um trajeto real. Os modelos permitiram o estudo da dinâmica longitudinal e podem ser posteriormente utilizados para estudos relacionados a emissões de gases poluentes.

Como proposta de trabalho futuro a ser desenvolvido a partir dos resultados obtidos neste trabalho, sugere-se o desenvolvimento de um módulo que permita estabelecer estratégias de mudança de marchas para o modelo do Amesim para diferentes ciclos de condução. 


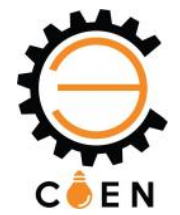

Outra possível abordagem futura a ser desenvolvida é a adoção de configurações híbridas nos dois modelos que busquem aproveitar a energia dissipada nos momentos de frenagens do automóvel, realizando comparações entre os resultados obtidos para ambos dos modelos.

\section{DIREITOS AUTORAIS}

Os autores são os únicos responsáveis pelo conteúdo das informações contidas neste artigo.

\section{REFERÊNCIAS}

BASTOS, F. C.. Análise da Influência dos Métodos de Cálculo da Força Resistiva Total ao Deslocamento de um Veículo Leve na Determinação do Consumo de Combustível e na Emissão de CO2 no Ciclo Urbano. Dissertação de Pós-Graduação em Engenharia Mecânica - Universidade Federal de Minas Gerais, 133 p., 2003.

BERTO, L. F. Modelagem Dinâmica de Sistema Automotivo: Estudo de Caso via Testes de Performance e Falhas do Baja SAE.. Dissertação de Mestrado em Engenharia Mecânica Universidade Federal de Santa Catarina, 210 p., 2015.

BERTON, H. L.; BADUY, R. E. G. Estudo Preliminar de Alternativas de Transmissões Hidrostáticas Aplicáveis ao Protótipo Baja. Trabalho de Conclusão de Curso (Graduação em Engenharia Mecânica) - Universidade Tecnológica Federal do Paraná, 210 p., 2012.

CORRÊA, F.C.; SILVA, L.C.; DEDINI, F.G. Fuzzy Control for Hybrid Vehicle. 21st Brazilian Congress of Mechanical Engineering, v. 1, pp. 1-9, 2011.

HENNEK, K.; SZYMON K.; MARIUSZ G.; JAROSŁAW M. Analysis of Fuel Consumption in Real Driving Cycles. Proceedings of the Institute of Vehicles, [S. 1.], v. 110, n. 1, pp. 31-38, 2017.

MORETTI, R. R.; Mistura Diesel, Biodiesel e Etanol Anidro: uma Possibilidade para Reduzir o Custo da Cadeia de Produção da Cana-de-Açúcar. Dissertação de Mestrado em Engenharia Mecânica - Universidade Estadual de Campinas, 98 p., 2013.

NATIONAL RENEWABLE ENERGY LABORATORY. Chapter 1:Introduction - ADVISOR Documentation. [S. 1.], 2003. Disponível em: <http://adv-vehiclesim.sourceforge.net/advisor_ch1.html\#1.0>. Acesso em: 18 jun. 2019.

OLIVEIRA, J. F. A.; NOGUEIRA, L. A. H.; HORTA, D. P. Modelagem e Simulação de Veículos Automotores Leves para Estimativa do Consumo e Emissões. XXVI Simpósio Internacional de Engenharia Automotiva, São Paulo, São Paulo, Vol. 1, pp. 415-432, 2018.

TRINDADE, I. M. Modelagem, Controle e Otimização de Consumo de Combustível para um Veículo Híbrido Elétrico Série-Paralelo. Dissertação de Mestrado em Ciências - Escola Politécnica da Universidade de São Paulo, 195 p., 2016.

SEBECK, K.; JAMIE, M.; JEREMY, M; DENISE, M. R. Characterization of Army Ground Vehicle Drive Cycles. GVSETS MSTV, Vol. 1, [S. I.], [S. 1.: s. n.], 2017. 


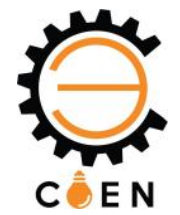

SEQUENZ, H. Emission Modelling and Model-Based Optimisation of the Engine Control. Dissertação de Doutorado em Engenharia Elétrica - Universidade Técnica de Darmstadt, 188 p., 2012.

SILVA, J. C.; NASCIMENTO, J. C. Modelagem e Simulação Dinâmica: AMESim-Ambiente para Protótipos Virtuais. Revista da ABHP Associação Brasileira de Hidráulica e Pneumática. v. 1, p. 4-8, 2002.

SIEMENS PLM SOFTWARE. Simcenter Amesim. [S. 1.], 2019. Disponível em: <https://www.plm.automation.siemens.com/global/en/products/simcenter/simcenteramesim.html $>$. Acesso em: 19 maio 2019.

THOMAS, V.; TALON, V. Deployment of System Simulation as a Support Tool for the Control Development. IFAC Proceedings Volumes, v. 45, n. 30, p. 184-190, 2012.

X-ENGINEER. What Drives forward R\&D for passenger vehicles and powertrain systems?. In: X-Engineer. Drivetrain. [S. 1.: s. n.], 2019. Disponível em: <https://x-engineer.org/automotiveengineering/drivetrain/awd-technologies/types-four-wheel-drive-4wd-all-wheel-drive-awdsystems/>. Acesso em: 3 abr. 2019.

\title{
MODELING OF A VEHICLE WITH INTERNAL COMBUSTION ENGINE AND VALIDATION WITH DATA OF A REAL DRIVE CYCLE
}

\author{
Wenderson Cirilo Silva de Paula ${ }^{(1)}$ (endersoncsdep@gmail.com), Tarsis Prado Barbosa ${ }^{(1,2)}$ \\ (tarsisbarbosa@ufsj.edu.br), Leonardo Adolpho Rodrigues da Silva ${ }^{(1)}$ (leonardo@ufsj.edu.br), Juan Carlos \\ Horta Gutiérrez ${ }^{(2)}$ (horta@ demec.ufmg.br) \\ ${ }^{(1)}$ Universidade Federal de São João del-Rei (UFSJ) - Dep. das Engenharias de Telecom. e Mecatrônica - Ouro Branco - MG \\ (2) Universidade Federal de Minas Gerais (UFMG) - Dep. de Engenharia Mecânica - Belo Horizonte - MG
}

ABSTRACT: This work objective is to develop computational models of a cargo vehicle in two different simulation programs - Advisor and Amesim, aiming to investigate the possibilities and limitations of both. The models were simulated in a driving cycle obtained in a route performed with the real vehicle. The error of the average fuel consumption of the two models implemented was less than $2 \%$ in relation to the value measured with the real vehicle in the route studied.

KEYWORDS: Computational Modeling, Powertrain, Consumption Analysis, Performance Analysis. 